\title{
Study on Fires Following the 2011 Great East-Japan Earthquake based on the Questionnaire Survey to Fire Departments in Affected Areas
}

\author{
AI SEKIZAWA ${ }^{* 1}$ and KATSUNORI SASAKI ${ }^{* 2}$ \\ *1 Graduate School of Global Fire Science and Technology, Tokyo University of Science \\ 1-3, Kagurazaka, Shinjuku Ward, Tokyo 162-8601, Japan \\ *2 Earthquake Engineering Group, OYO Corporation \\ 43, Miyukigaoka, Tsukuba, Ibaraki, 305-0841, Japan
}

\begin{abstract}
The 2011 Great East-Japan Earthquake of March 11, 2011, caused large-scale fire damage across a wide area, with the type and extent of fire damage exceeding that caused by the 1995 Kobe Earthquake. A particularly distinctive characteristic was the many fires caused either directly or indirectly by the tsunami. The mechanism of occurrence and development of tsunami-induced fires differs significantly from typical earthquake-induced fires. Given these two very different types of initiation scenarios, fires following the Great East-Japan Earthquake were analyzed based on factors such as regional distribution, causes of ignition, pattern of fire development and spread, and size of fire. Data for these analyses were collected from questionnaire surveys of fire departments located in the affected areas. In addition, data are presented on the relationship between seismic intensity and the incidence of earthquake-induced fires. A significant finding from the analysis is that, given the impacts to infrastructure and extent of damage, tsunami-induced fires are likely to spread beyond the control of fire brigades. Therefore, the prevention and mitigation of tsunami-induced fires in the future earthquakes is of great significance.
\end{abstract}

KEYWORDS: post-earthquake fire, tsunami, statistics, fire investigation

\section{INTRODUCTION}

The earthquake of March 11, 2011, officially named as the "2011 off-the-Pacific-coast of Tohoku Earthquake,” but herein referred to the Great East-Japan Earthquake, was one of the largest magnitude earthquakes ever recorded. To put it in context, the scale is such that earthquakes of this magnitude are estimated to occur only once every 1,000 years. The Great East-Japan Earthquake caused damage of unimaginable proportions, generating a tsunami which caused widespread and large-scale damage to buildings and infrastructure, followed by accidents at a nuclear power plant, the collapse of buildings and the spread of fire. In total, this disaster resulted in approximately 20,000 dead and missing persons. Although the damage caused by fire was not comparable with the tsunami damage in terms of ferocity and severity, the fire damage was nonetheless very large and widespread. In order of impact, the scale and the diversity of fire damage in this earthquake is comparable only to that of the 1995 Kobe Earthquake and the 1923 Great Kanto Earthquake.

Unlike the 1995 Kobe Earthquake and the 1923 Great Kanto Earthquake, this earthquake presented the unprecedented and distinctive characteristic of fires following tsunami. The investigation and elucidation of this type of fire ignition and resulting damage is extremely important for developing measures to mitigate future possible fire losses following earthquakes and tsunami. To obtain data on both the tsunami-induced and earthquake-induced fires, the authors conducted a questionnaire survey of fire departments in the affected areas. Pertinent fire departments were identified based on where the outbreak of fires had been reported in the "News (136th Edition) on the 2011 off the Pacific coast of Tohoku Earthquake as of August 11, 2011"[1] announced by the Fire and Disaster Management Agency.

Fig. 1 shows a map of the distribution of 293 fire outbreaks as obtained from the questionnaire survey, which is described in more detail below. As seen in Fig.1, numerous fires were affected in some way by the tsunami (white circle), and are herein referred to as "tsunami-induced fires." All fires not affected by the tsunami (grey and black circles) are herein referred to as "earthquake-induced fires." Since the mechanism of occurrence and development of "tsunami-induced fires" differs largely from those of "earthquakeinduced fires," these two types of fires are analyzed separately. 
Related studies on fires caused by the Great East Japan-Earthquake include a report of 106 fire cases obtained from the survey of 28 fire departments in the affected areas by Kindaishobosha [2] and a summary report of fire information on 81 fires obtained from the interviews with the fire department headquarters by Iwami et al. [3][4]. While both of these studies provided valuable information, they reflected only a small percentage of the total fires, especially if compared with this study, which received responses from $88.3 \%$ of the sixty fire departments in regions where the outbreak of post-earthquake fires were reported.

Currently, the Japan Association for Fire Science and Engineering, Committee on Post-Earthquake Fire, is conducting analysis related to areas damaged by fires, building damage, and/or casualties using data obtained from their own questionnaire survey [5]. However, the analysis of this study is preliminary at this point and additional research is required for completion of the detailed report.

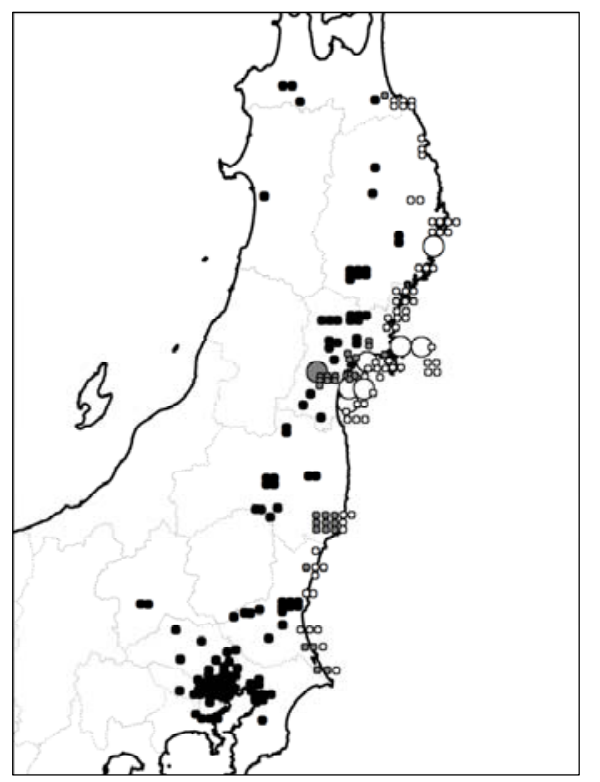

$$
\begin{aligned}
& \text { Explanatory note } \\
& \text { Earthquake-induced fire in an inland area } \\
& \text { Earthquake-induced fire in a coastal area } \\
& \text { Tsunami-induced fire in a coastal area }
\end{aligned}
$$

Number of fires by size of a circle

10 fires

- 1 fires

10 fires

- 1 fires

10 fires

○ 1 fires

Fig.1. Distribution of fires following the Great-East Japan Earthquake by type and number of fire for the 293 fires obtained by the questionnaire survey.

\section{QUESTIONNAIRE SURVERY AND DATA}

\section{Outline of Questionnaire Survey}

Questionnaires were sent to the sixty fire departments having jurisdiction over the areas affected by the earthquake roughly six months after the earthquake. The survey period was from the beginning of September to the end of October 2011. In these sixty fire departments, there was at least one reported fire outbreak on the list of "the News on the 2011 off-the-Pacific-coast of Tohoku Earthquake as of August 11, 2011" announced by the Fire and Disaster Management Agency [1].

The authors received the responses to the questionnaires from fifty-three fire departments out of the sixty departments involved in the survey, yielding a response ratio of $88.3 \%$. The authors believe that an $88.3 \%$ response ratio is satisfactory for the purpose of reflecting the entire spectrum of the post-earthquake fires in this event.

The total number of post-earthquake fires obtained through this survey was 293. This number is slightly larger than the 287 post-earthquake fires reported by the Fire and Disaster Management Agency as of August 11, 2011. The authors understand that slight increase reflects cases certified after August 11, 2011, as earthquake-related fires and therefore not included in the aforementioned report by Fire and Disaster Management Agency.

Since the data were obtained through the questionnaire surveys sent to fire departments, some limitations may exist, such as slight differences in the determination of earthquake-induced fires and tsunami-induced fires, along with the fact that not all fire departments replied to all questions. 
The outline of the survey is as follows.

1) Period of survey: Two months from the beginning of September to the end of October, 2011

2) Method of survey: Sending and collecting a questionnaire by postal mail or by E-mail in response to the request from each fire department surveyed.

3) Question items:

- Time (date and time) of fire outbreak and time of fire report to the fire station

- Death toll and the number of injured

- Distinction of an earthquake-induced fire or a tsunami-induced fire

- Extent of fire damage (small fire, partially burned down, half burned down, totally burnout, etc.)

- Type of fire (structure fire, vehicle fire, rubble fire, fire of these mixtures, etc.)

- Fire cause

- Type of use and type of construction, if it is the case of a structure fire

- How a fire was reported to a fire station (descriptive information)

- Outline of a fire itself and the fire-fighting with it (descriptive information)

\section{Data Subject to the Analysis}

Fig. 2 shows the chronological timeline of the cumulative distribution of fire outbreaks for the 293 fires obtained by the questionnaire survey. After the main earthquake on March 11, 2011, several strong aftershocks occurred, quite frequently, with the largest one on April 7, 2011. In addition, there were other lingering influences from the tsunami. As such, several fires may have initiated after the initial earthquake but as still resulting from the earthquake, tsunami or related factors. Due to the uncertainty regarding fire initiation times significantly after the initial earthquake, the authors decided to target the 269 fires that occurred in March. This represents $91 \%$ of all post-earthquake fires obtained by the survey. There is high confidence that these fires are directly or indirectly influenced by the earthquake motion and the tsunami.

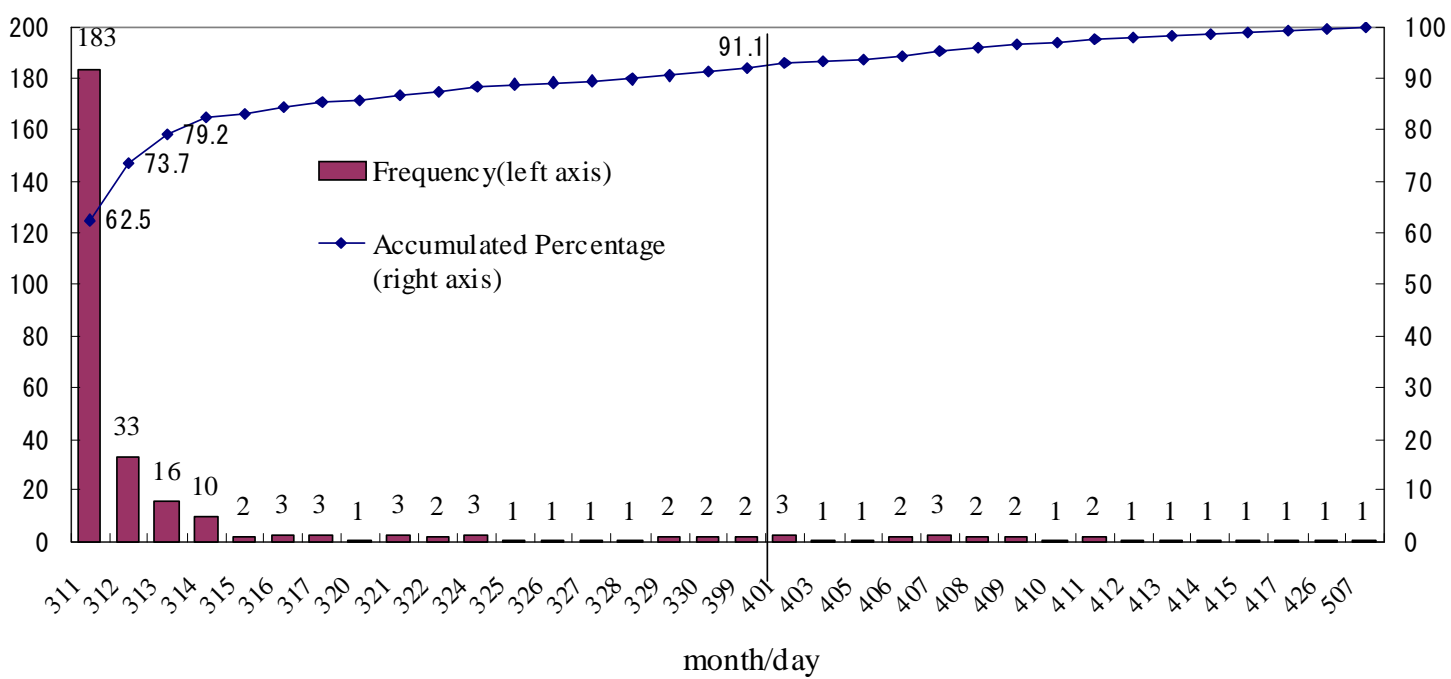

Fig. 2. Chronological timeline of fire incidents. (For the 293 fires obtained by the questionnaire survey) *Note: (399) stands for the fires that occurred in the month of March but its date is unknown.

The 269 fires studied were divided into three categories: fires in the inland area, which had never been affected by tsunami, fires in the coastal area but not affected by tsunami, and fires affected by tsunami. This categorization was made based on the responses in the questionnaire by fire departments in the coastal area by distinguishing whether or not a fire was affected by tsunami. 
The information gathered is summarized in Table 1. Out of the total 269 fires studied, 124 fires, or roughly half of the fires (46.1\%), were tsunami-induced fires, 36 fires (13.4\%) were earthquake-induced fires located in the coastal area, and the remaining 109 fires (40.5\%) were conventional earthquake-induced fires which started in the inland areas. The distinction between "earthquake-induced fire" versus "tsunamiinduced fire," and between "inland area” versus "coastal area," are used by the authors in the analysis of the fires and reporting of the results.

Table 1. Information of post-earthquake fires by prefecture.

\begin{tabular}{|r|r|r|r|r|}
\hline & $\begin{array}{c}\text { Inland area } \\
\text { Earthquake-induced } \\
\text { fires }\end{array}$ & $\begin{array}{c}\text { Coastal area } \\
\text { Earthquake-induced } \\
\text { fires }\end{array}$ & $\begin{array}{c}\text { Coastal area } \\
\text { Tsunami-induced } \\
\text { fires }\end{array}$ & \multicolumn{1}{|c|}{ Total } \\
\hline Aomori Prefecture & 3 & 1 & 6 & 24 \\
\hline Iwate Prefecture & 9 & 0 & 82 & 10 \\
\hline Miyagi Prefecture & 10 & 25 & 4 & 21 \\
\hline Fukushima Prefecture & 12 & 5 & 8 & 26 \\
\hline Ibaraki Prefecture & 13 & 5 & 0 & 2 \\
\hline Gunma Prefecture & 2 & 0 & 0 & 11 \\
\hline Saitama Prefecture & 11 & 0 & 0 & 11 \\
\hline Chiba Prefecture & 11 & 0 & 0 & 32 \\
\hline Tokyo Metropolitan Area* & 32 & 0 & 0 & 6 \\
\hline Kanagawa Prefecture & 6 & 0 & 124 & 269 \\
\hline Total & 109 & 36 & & \\
\hline *From Tokyo Fire Department & & & & \\
\hline
\end{tabular}

\section{RESULTS AND DISCUSSION}

\section{Building Collapse Ratio and Fire Outbreak Ratio versus Seismic Intensity}

In this section the relationships between building collapse ratio and fire outbreak ratio versus seismic intensity are explored for the earthquake-induced fires in the inland area.

From the survey, a total of 109 fires broke out in the inland area. In addition, there were seven other inland fires listed in [1]. Although we did not receive the responses about these seven fires through the questionnaire survey, they are included in the analysis because they were obviously earthquake-induced fires. This resulted in a total of 116 inland fires analyzed with respect to the relationship between the seismic intensity and the fire outbreak ratio and the building collapse ratio by municipality. ${ }^{1}$

In this study, the measure of seismic intensity to indicate the strength of ground motion in each affected area is expressed in the official scale announced by Japan Meteorological Agency (JMA), which ranges from level one, the smallest to level seven, the strongest. The expression of upper or lower in some levels such as upper- 6 or lower- 6 is used to indicate the interim level of integer value of the seismic intensity. The JMA seismic intensity scale does not express the size of magnitude of an earthquake itself, but expresses the strength of ground motion in each area impacted by the quake.

Fig. 3 and Fig. 4 show the relationship between building collapse ratio and fire outbreak ratio of earthquake-induced fires versus seismic intensity, respectively. In both of the figures, a large gap in the building collapse ratio and fire outbreak ratio appears between "upper-5 and under" and "lower-6" in seismic intensity. According to the figures, very few buildings collapsed and very few fires broke out in the range where the seismic intensity is upper-5 and under.

\footnotetext{
${ }^{1}$ The authors included the data of municipalities without fire damage but with building damage in the analysis because it helps to provide a more complete picture of the damage situation.
} 
In the case of the 1995 Kobe Earthquake, the number of totally collapsed buildings in the whole Kobe City was about 67,000[6]. When converted to the number per 100,000 persons, the number of buildings which collapsed completely was 4,400, since the population in Kobe at that time was 1.52 million. The seismic intensity in many areas of Kobe City was upper-6 and/or 7 in the Kobe Earthquake.

Although there is a slight difference in seismic intensity between the two earthquakes, comparison of the fire damage in the two events is worthwhile. Fig. 3 shows that the Great East-Japan Earthquake resulted in damage to buildings of roughly one-tenth that experienced in the Kobe Earthquake (4,400 damaged buildings per 100,000 persons in the Kobe Earthquake and 523 damaged buildings per 100,000 persons in the Great East-Japan Earthquake in the seismic intensity of upper-6 area, roughly equivalent to the Kobe Earthquake).

Looking at fires, in the Great East-Japan Earthquake, the number of fire outbreaks per 100,000 persons is 0.82 for seismic intensities of lower- 6 area and 0.64 in the upper- 6 area. This is shown in Fig.4. The lower number of outbreaks for higher intensities may be attributed to the limited data for the area in the intensity of upper-6. In comparison, the number of post-earthquake fires in Kobe City due to the Kobe Earthquake is 175, which is about 11.5 fires per 100,000 persons. This value is much larger than that of the Great EastJapan earthquake, even if compared with the fire incidence in intensity of lower- 6 area (0.82) which was the largest shown in Fig. 4.

Thus, comparing the damage from the Great East-Japan Earthquake with that from the Kobe Earthquake, it can be said that both the ratios of building collapse and fire outbreak per 100,000 persons in the Great EastJapan Earthquake were much smaller: roughly one tenth that of the Kobe Earthquake. One credible reason for this is that the component of ground motions in the periods ranging from 1 to 2 seconds in the Great East Japan Earthquake was smaller by $70 \%-80 \%$ than experienced in the Kobe Earthquake [7]. The ground motion with periods ranging from 1 to 2 seconds is likely to cause building damage on low-rise wooden houses and hence it is often referred to as "killer pulse".

\section{Building collapse ratio:}

Number of collapsed buildings per 100,000 persons

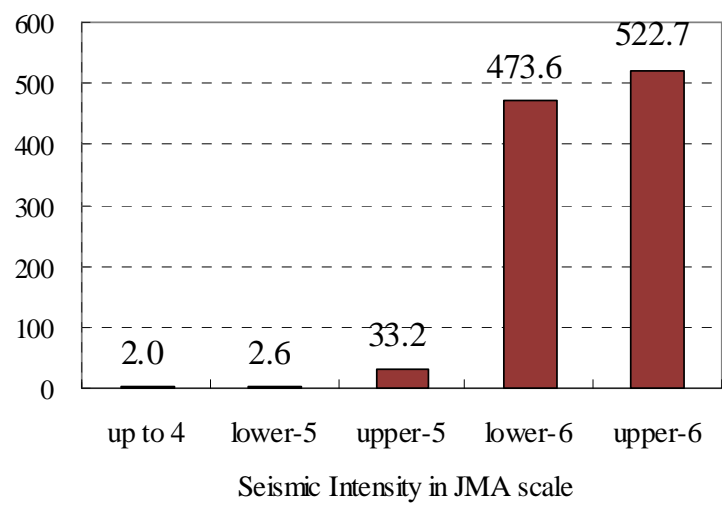

Fig.3. Building collapse ratio versus seismic intensity in JMA scale.
Fire outbreak ratio:

Number of fire outbreaks per 100,000 persons

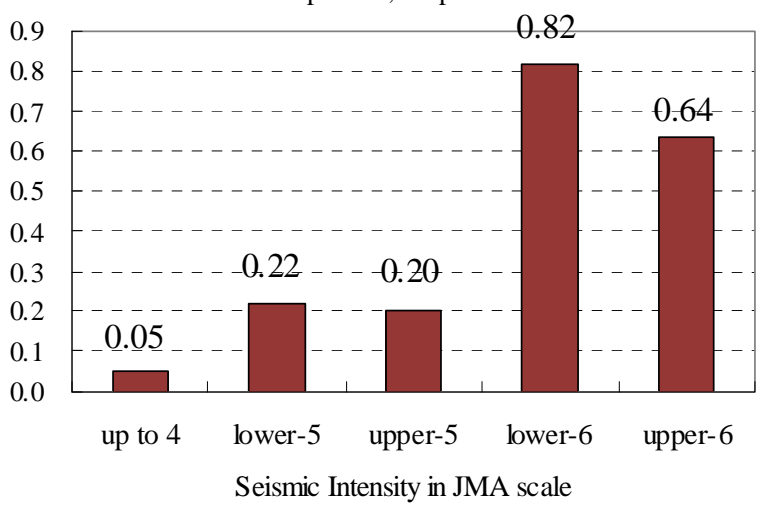

Fig.4. Fire outbreak ratio of earthquake-induced fires versus seismic intensity in JMA scale.

\section{Building Collapse Ratio and Fire Outbreak Ratio versus Peak Ground Acceleration (PGA)}

Fig. 5 and Fig.6 show the relation of peak ground acceleration (abbreviated as "PGA" below) with the building collapse ratio and the fire outbreak ratio per population of 100,000 persons respectively. PGA is a measure of earthquake acceleration on the ground and can be expressed in Gal, where $1 \mathrm{Gal}$ is equal to 0.01 $\mathrm{m} / \mathrm{s}^{2}$. Fig. 5 demonstrates a good correlation of the building collapse ratio and PGA. As PGA reaches to $400 \mathrm{Gal}$, the building collapse ratio begins to rise and increases exponentially with PGA. Fig. 6 shows that the fire outbreak ratio leaps upward steeply in the range when PGA reaches 700 Gal, while the fire outbreak ratio was just slightly more than 0.2 , and was rather low in comparison, when in the range of 600 Gal or less. This has a resemblance to the gap of the fire outbreak ratio between seismic intensity upper-5 
and lower-6 as seen in Fig. 4. The smaller number at PGA=800 Gal is again probably attributed to limited data.

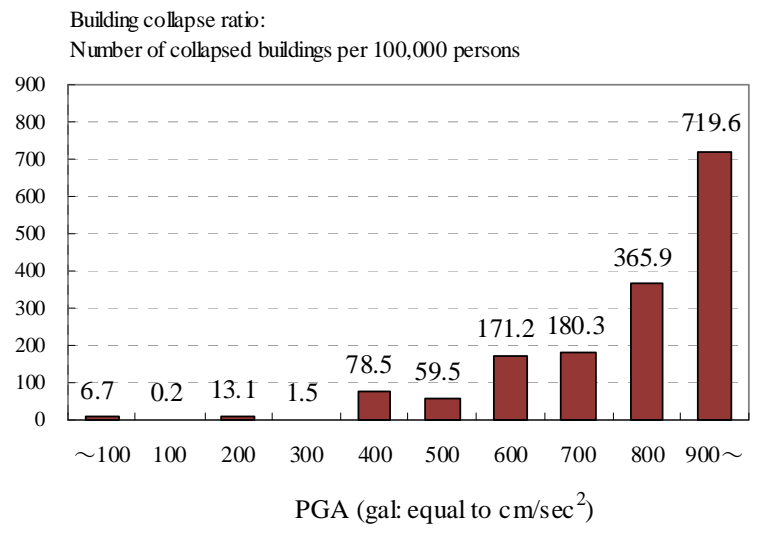

Fig.5. Building collapse ratio versus peak ground acceleration.

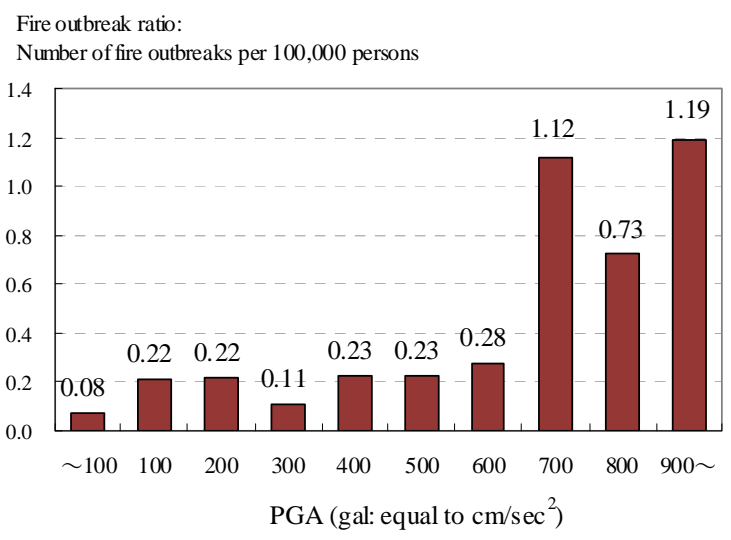

Fig.6. Fire outbreak ratio of earthquake-induced fires versus peak ground acceleration.

\section{Time of Fire Outbreak}

Fig. 7 shows the breakdown of time of fire outbreak by earthquake-induced fires and tsunami-induced fires for the 269 fires which occurred within the month of March. Two-thirds of both earthquake-induced fires and tsunami-induced fires occurred on the very day of the earthquake, March 11, 2011. 91.8\% of the earthquake-induced fires occurred within three days after the main earthquake. $82.2 \%$ of the tsunamiinduced fires occurred within the same period. The remaining 16.1\% occurred after March 13.

\section{Type of Fire}

Fig. 8 shows the type of fire by earthquake-induced fires and tsunami-induced fires for the 269 fires that occurred within March. From this figure, it is obvious that there is large difference between earthquakeinduced fires and tsunami-induced fires with regard to the type of fire. 91.0\% of earthquake-induced fires were structure fires, but the share of structure fires in tsunami-induced fires was only $21.0 \%$. By contrast, the two main types of tsunami-induced fires were vehicle fires (32.3\%) and rubble fires (33.9\%). In addition, there were also $4.0 \%$ of unique cases, where the fire was breaking out while both vehicles and houses were being swept up together by tsunami. The large share of vehicle fires in tsunami-induced fires is worth noting. Since there is uncountable number of vehicles in densely inhabited areas, there could be many fire outbreaks from vehicles in future earthquakes, if preventive measures are not taken.

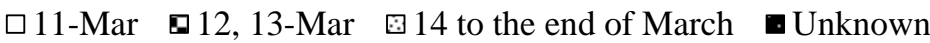

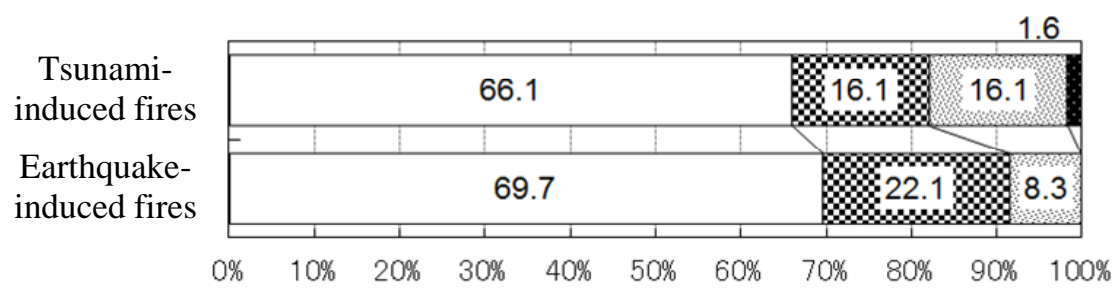

Fig. 7. Time of fire outbreak by earthquake-induced fires and tsunami-induced fires for the 269 fires that occurred within March. 


\section{Type of Use for Earthquake-induced Structure Fires}

Fig. 9 shows the breakdown of building use according to the inland area and the coastal area for the earthquake-induced fire. Half of the building uses are residential, one- or two-family dwellings and apartment houses, both in the inland area and in the coastal area. 15.6\% of the earthquake-induced fires in the inland area were in factories and work places.

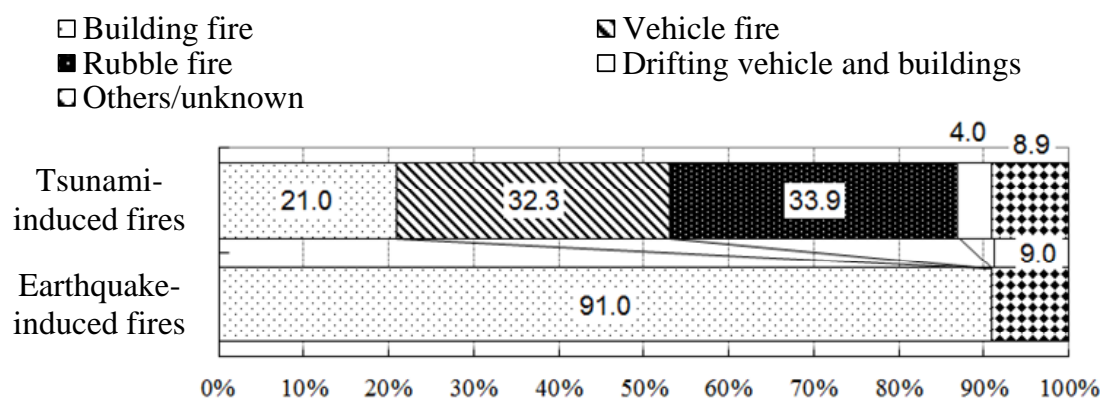

Fig. 8. Type of fire by earthquake-induced fires and tsunami-induced fires for the 269 fires that occurred within March.

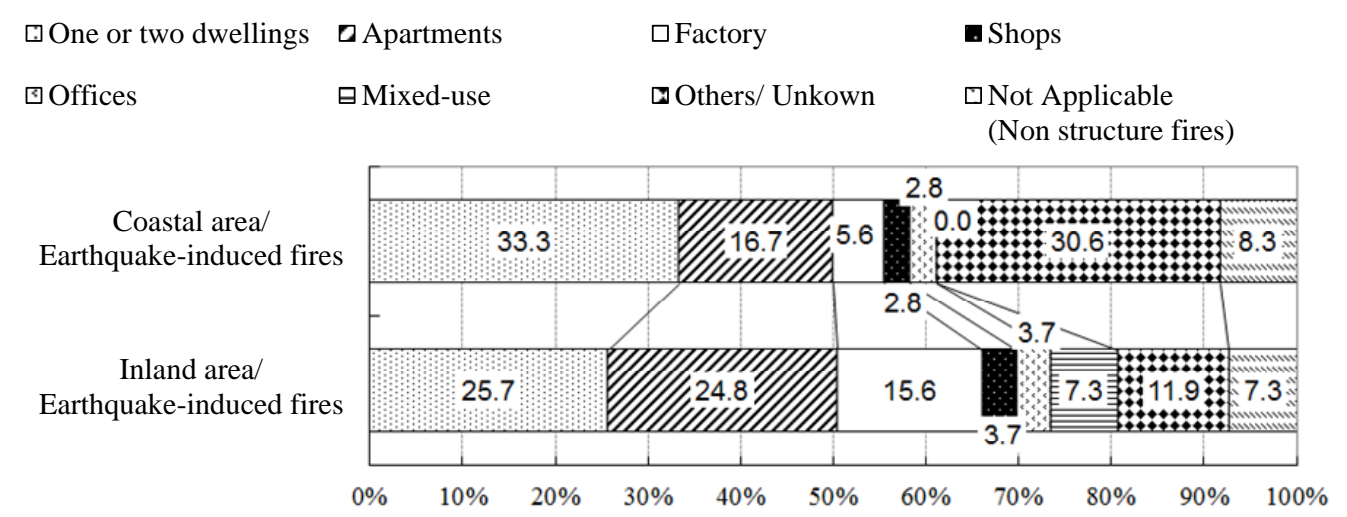

Fig. 9. Type of use for earthquake-induced structure fires by the area affected. $\quad(n=145)$

\section{Fire Cause}

The breakdown of fire causes is shown in Table 2. For the earthquake-induced fires, the majority of fire causes involved appliances with a heating source, such as space heaters, cooking stoves, and candles that overturned and fell by the shock of the earthquake. These cases accounted for $45.5 \%$, or nearly half of all causes. Out of these, there was a unique case that an aquarium for tropical fish in a home started a fire when power failure was restored after it was overturned and lost the water inside. On the other hand, 38 cases (26.2\%) were caused by destruction and breakage of gas piping or electric wiring, accounting for about a quarter of all fires.

In Table2, the $6.9 \%$ of "unknown" fire causes for earthquake-induced fires is not surprising, since the percentage of "unknown" fire cause among all the daily fires in Japan in 2009 is $11.9 \%$ according to the White Book on Fire Service (2010 Edition)[8]. As for the earthquake-induced fires, determination of fire causes is rather easier if compared with daily fire causes because they were caused directly by the earthquake motion.

Looking closer into the causes of earthquake-induced fires in residential homes as shown in Fig. 10, the major fire causes were overturning and falling of appliances with heat sources onto combustibles, which 
accounted for as many as $72.0 \%$ of the ignitions. In addition, Fig.11 gives a further breakdown of firecauses for the 54 cases of fire outbreak due to appliances with heat sources and combustible materials. According to the energy source, electric appliance accounts for 28 cases, so it occupies more than half (51.9\%). The number of fires due to gas appliances and oil appliances was only 3 cases (5.6\%) respectively.

As shown in Fig. 11, 18 cases out of 54 (24.8\%) were caused by overturning and falling of the candles which were being used for lighting purpose during the power outage. These are considered to be cases which resulted in outbreak of fire due to carelessness related to use of open flame sources for lighting during a power outage or non-artificial falling by an aftershock.

during a power outage resulting from aftershock or accident).

By contrast, in Table 2, the major outbreak patterns of tsunami-induced fires were fires from drifting rubble (33.9\%), short circuit/spark by submergence of electrical source (21.8\%) and unknown causes (25.8\%). These include the fires which were assumed to occur from the electrical equipment of flooded vehicles or inundated power meters. $10.5 \%$ of tsunami-induced fires occurred through breaking and loose connection of electrical wiring due to the destructive force of tsunami. The fires from the drifting rubble is thought to include fire cases due to gas leakage from drifting LPG cylinders and vehicle fires in collision with another cars and/or buildings. Both of the above cases were often witnessed by various testimony and recorded images. However, these fire causes have not been deterministically identified as so to date, because fire departments did not have the capacity to investigate into these fires in detail when the fires occurred.

Table 2. Breakdown of fire causes by earthquake-induced and tsunami-induced fires.

\begin{tabular}{|c|c|c|c|}
\hline Cause of fire & Similar groups & $\begin{array}{c}\text { Earthquake- } \\
\text { induced fires (\%) }\end{array}$ & $\begin{array}{l}\text { Tsunami-induced } \\
\text { fires (\%) }\end{array}$ \\
\hline $\begin{array}{l}\text { Falling over of heaters and } \\
\text { combustibles on it }\end{array}$ & \multirow{6}{*}{$\begin{array}{l}\text { Due to falling of } \\
\text { fire appliances and } \\
\text { combustible } \\
\text { materials }\end{array}$} & 24.8 & 0.0 \\
\hline Candles falling/tipping over & & 12.4 & 0.0 \\
\hline $\begin{array}{l}\text { Falling over of gas stoves and } \\
\text { combustibles on it }\end{array}$ & & 3.4 & 0.0 \\
\hline Overheating of aquarium heater & & 4.1 & 0.0 \\
\hline $\begin{array}{l}\text { Chemical fire (such as by } \\
\text { mixing) }\end{array}$ & & 0.7 & 0.0 \\
\hline Subtotal & & 45.5 & 0.0 \\
\hline Gas leak (such as broken pipe) & \multirow{3}{*}{$\begin{array}{l}\text { Due to damages in } \\
\text { gas piping and } \\
\text { electrical wiring }\end{array}$} & 4.1 & 0.8 \\
\hline Break in circuit/electrical short & & 22.1 & 10.5 \\
\hline Subtotal & & 26.2 & 11.3 \\
\hline Drifting rubble caught on fire & \multirow{4}{*}{$\begin{array}{l}\text { Due to tsunami } \\
\text { and inundation }\end{array}$} & 0.0 & 33.9 \\
\hline $\begin{array}{l}\text { Electrical short and spark (due } \\
\text { to flooding) }\end{array}$ & & 0.0 & 21.8 \\
\hline Spontaneous combustion & & 0.0 & 2.4 \\
\hline Subtotal & & 0.0 & 58.1 \\
\hline Others (electrically related) & & 4.8 & 4.0 \\
\hline $\begin{array}{l}\text { Others (other than electrical } \\
\text { causes) }\end{array}$ & & 16.6 & 0.8 \\
\hline Unknown & & 6.9 & 25.8 \\
\hline Total & & $\begin{array}{r}100.0 \\
(145 \text { fires })\end{array}$ & $\begin{array}{r}100.0 \\
\text { (124 fires) }\end{array}$ \\
\hline
\end{tabular}




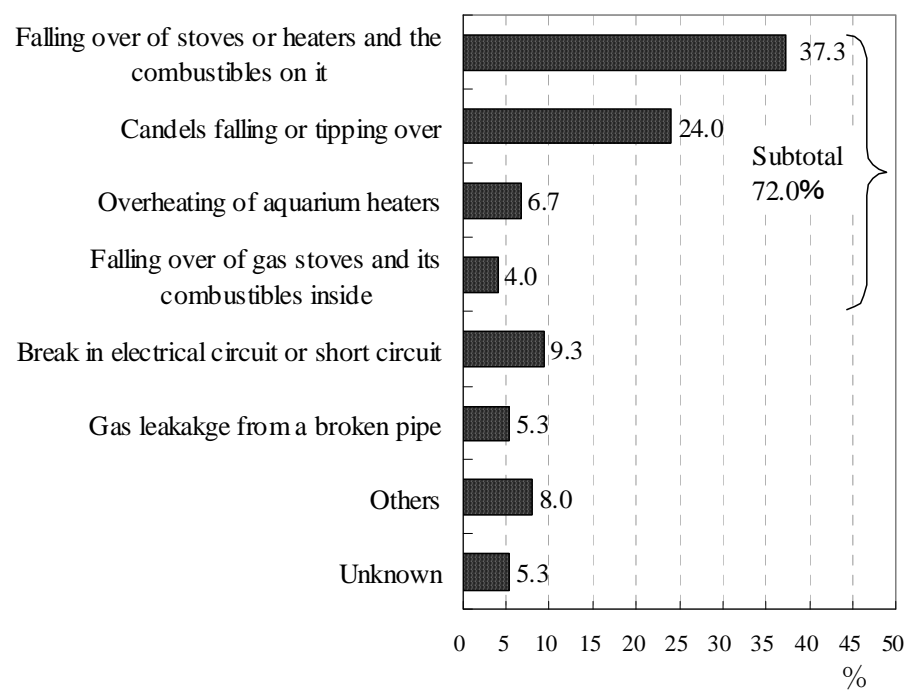

Fig.10. Causes of residential fires out of earthquake-induced fires. ( $\mathrm{n}=75)$

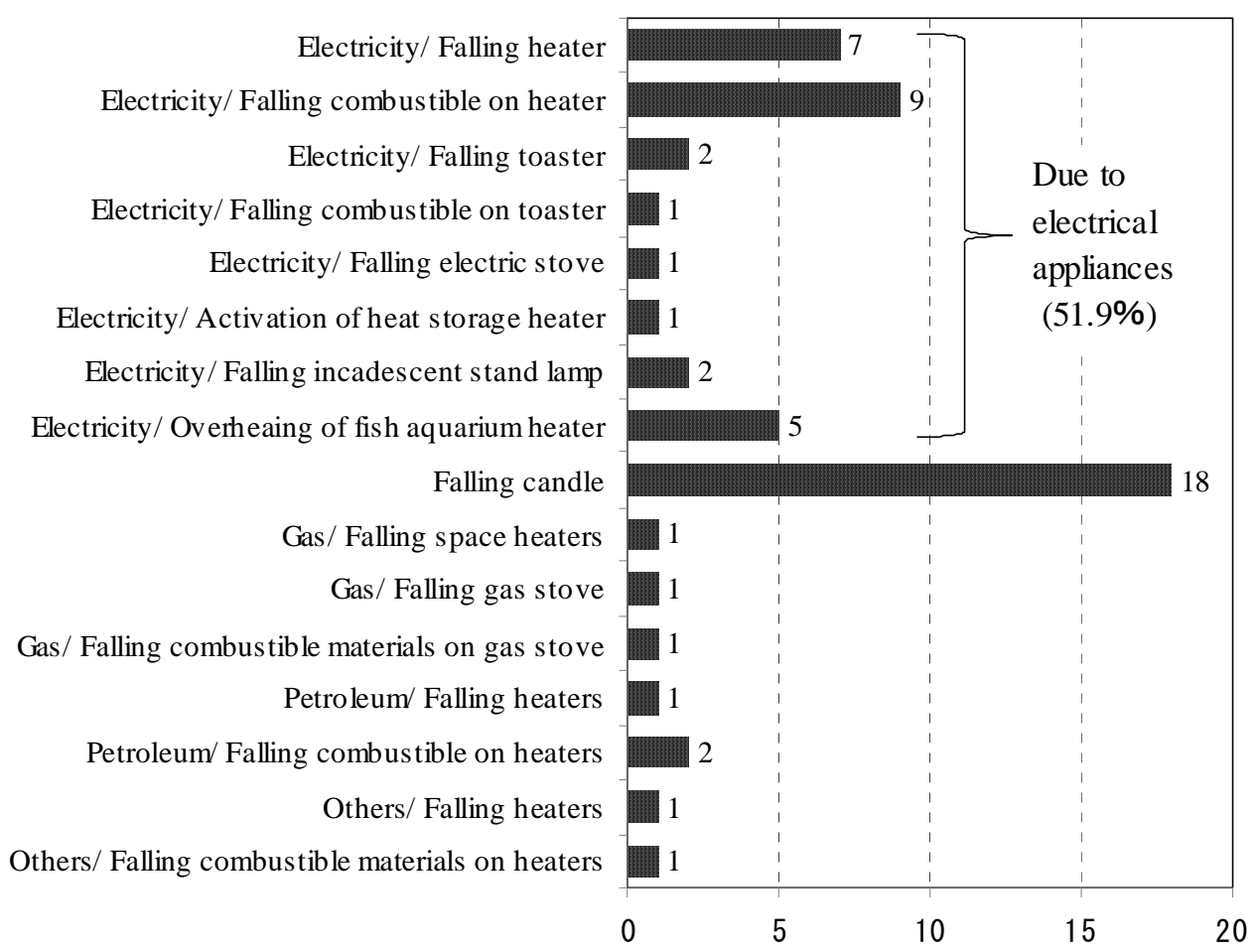

Fig.11. Breakdown of fire causes by used energy from residential occupancy relating to heating devices for earthquake-induced fires. $(\mathrm{n}=54)$.

\section{Fire Size by Type of Outbreak}

Fig. 12 and Fig. 13 show the breakdown of fire size by type of outbreak for earthquake-induced fires and tsunami-induced fires, respectively. As for tsunami-induced fires, "unknown" cases in fire size accounted for $59.7 \%$, which made up the vast majority. The fire size is treated as unknown if it broke out after the built-up area was destroyed and reduced to piles of rubble by tsunami, even if it was a large fire. This is 
because the houses were already destroyed before the fire and hence the concrete number of buildings damaged was no longer countable.

Nevertheless, out of the other $40 \%$, a totally burned and a large scale fire (referring to 5 buildings or more damaged by fire) accounted for $29.9 \%$, and the percentage of half burned or smaller size of fire made up only $10.5 \%$ of the total. Therefore, one can imagine that the damage caused by tsunami-induced fires was serious in general. On the other hand, with the earthquake-induced fires, the percentage of partially burned fire or smaller size of fires accounted for $59.3 \%$ and in turn the percentage of totally burned fire accounted for only $20.7 \%$, which is not so much different from the percentage under the normal condition.

Fig.14 shows the breakdown of the size of fire for the 174 fires by coastal versus inland area and earthquake-induced versus tsunami-induced fire, respectively. It is found that the aspect of the progress of a fire greatly varied according to the type of a fire as described above. As for earthquake-induced fires in the inland area, small fires accounted for $54.6 \%$ and partially burned fires accounted for $19.6 \%$. These two cases make for $74.2 \%$ of the total number of earthquake-induced fires in the inland area. In turn, the cases of totally burned or larger fires accounted for $20.6 \%$, which is almost the same or even smaller than that of similar size fires in the national statistics of structure fires under normal conditions. Therefore, this result indicates that fire brigades in the inland area were able to cope with earthquake-induced fires similarly as it took place under normal condition.

However, some differences in size of fire were observed within earthquake-induced fires if dividing fires into inland area and coastal area. The percentage of totally burned fires is $40.7 \%$, which is much higher than that of small fires at $25.9 \%$ in coastal area, while the percentage of totally burned or larger fires is only $20.6 \%$ in an inland area. This led to the authors' conclusion on the fact that the fire brigades in a coastal area had to devote their manpower and resources for responding to both tsunami disaster and the fires so that their response capabilities were forced to be dispersed.

As for tsunami-induced fires, totally burned fires (26.0\%) and large-scale fires (48.0\%) makes up for 74.0\% out of the total. On the other hand, the cases of partially burned and small fires accounted for only $24.0 \%$. This means that it was extremely difficult for fire brigades to effectively cope with tsunami-induced fires in the early stage after the occurrence of tsunami, because they could not reach the fire scene due to the tsunami flood and the blockage of access roads by the driven rubble along with no usable fire hydrant and cisterns.

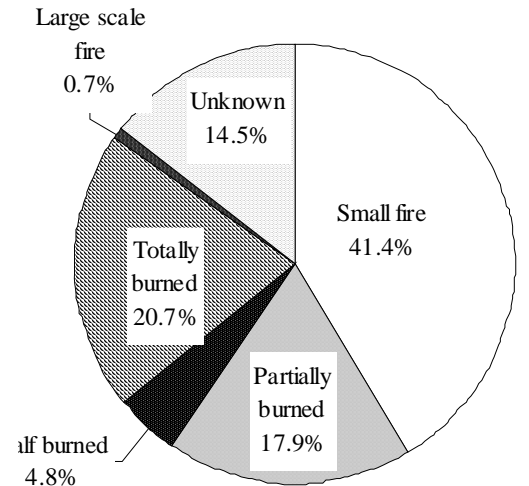

Fig. 12. Breakdown by size of fire for earthquake-induced fires. $(\mathrm{n}=145)$

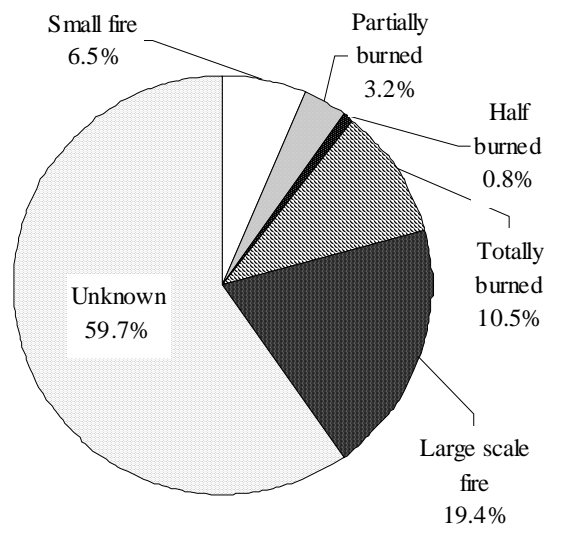

Fig. 13. Breakdown by size of fire for tsunami-induced fires. $(n=124)$ 


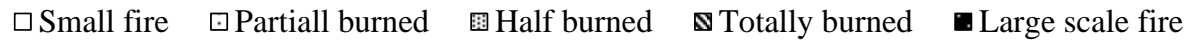

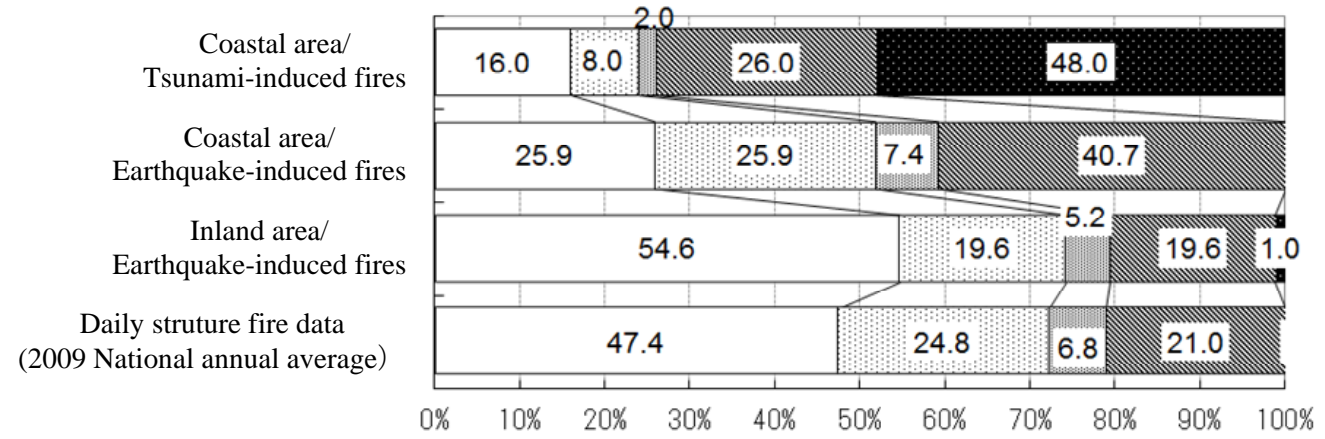

Fig.14. Breakdown by size of fire and by inland or coastal area relative to daily structure fires.

*Number of fires=174 (excluding fires whose fire size is unknown)

\section{Reporting Methods of Fires to a Fire Station by Type of Outbreak}

In Table 3, the breakdown by reporting methods of fires to a fire station is shown according to type of fire outbreak such as earthquake-induced or tsunami-induced and its location (inland or coastal area). In the inland area, out of all reporting methods, the emergency call 119 from a fixed line and/or a cell phone accounted for $69.7 \%$ (nearly $70 \%$ ), so it can be said that reporting a fire by a telephone seemed to be effective in this time.

On the other hand, there was not so much notification of fires by an emergency call with both earthquakeinduced fires and tsunami-induced fires in the coastal area. By contrast, the cases, where notification method is unknown, made up $55.6 \%$ of earthquake-induced fire and $28.9 \%$ of tsunami-induced fire, respectively. Further, as for tsunami-induced fires, there were quite a few cases (23.4\%), in which fire brigades discovered a fire during dispatch. This situation might have happened when local residents were overwhelmed by a serious tsunami and accordingly had no room to report a fire even though they found it.

Table 3. Breakdown of how fires were reported to a fire station.

\begin{tabular}{|r|r|r|r|}
\hline Reporting method & $\begin{array}{c}\text { EQ-induced fires } \\
\text { in inland areas (\%) }\end{array}$ & $\begin{array}{c}\text { EQ-induced fires } \\
\text { in coastal areas (\%) }\end{array}$ & $\begin{array}{c}\text { Tsunami-induced fires } \\
\text { in coastal areas (\%) }\end{array}$ \\
\hline 119 fixed line phone & 39.4 & 16.7 & 1.6 \\
\hline 119 cellular phone & 30.3 & 19.4 & 3.1 \\
\hline Fixed line telephone & 1.8 & 2.8 & 1.6 \\
\hline Call to police station & 3.7 & 0.0 & 2.4 \\
\hline Fire department radio & 0.0 & 0.0 & 2.4 \\
\hline Rushed in and report & 4.6 & 0.0 & 23.4 \\
\hline Detected by fire brigades & 0.0 & 0.0 & 11.3 \\
\hline Notified later & 14.7 & 2.8 & 8.1 \\
\hline Others & 5.5 & 55.6 & 29.8 \\
\hline Unknown & 0.0 & $100.0(36)$ & $100.0(124)$ \\
\hline Total & $100.0(109)$ & &
\end{tabular}

*EQ stands for 'earthquake' 


\section{CONCLUSIONS}

The authors conducted questionnaire surveys of fire departments regarding post-earthquake fires that resulted from the 2011 Great East-Japan Earthquake. Surveys were sent to the 60 fire departments in the cities, towns and villages, where the earthquake-induced fires had been reported. Of the 60 fire departments surveyed, 53 fire departments responded. The return rate was $88.3 \%$, which was determined to be a satisfactory level for the purpose of obtaining a broad picture of fires following this earthquake. Based on the items investigated in the questionnaire survey, analysis was conducted on "tsunami-induced fires" and "earthquake-induced fires," further separating them into fires in an "inland area" and fires in a "coastal areas". The results and main findings are summarized as follows.

The relationships between building collapse and seismic intensity, and fire outbreak and seismic intensity, in the 2011 Great East-Japan Earthquake were quite low as compared to the 1995 Kobe earthquake. Each ratio was about one-tenth that observed during the Kobe Earthquake. One credible reason for this is that the component of ground motions in the periods ranging from 1 to 2 seconds in the Great East Japan Earthquake was smaller by $70 \%-80 \%$ than experienced in the Kobe Earthquake.

There were large differences between earthquake-induced fires and tsunami-induced fires in terms of the type of fire. While the most of the earthquake-induced fires were structure fires, the share of structure fires in tsunami-induced fires was only a small part of the total. In the tsunami-induced fires, the two main types of fires were vehicle fires and rubble fires.

The major fire cause of earthquake-induced fires was overturning and falling of fire appliances with heating elements, such as space heaters, cooking stoves, and candles onto combustibles as a result of ground motion. This accounted for nearly half of all causes. On the other hand, the major outbreak patterns of tsunami-induced fires were the fire from drifting rubble and the short circuits/sparks in vehicles or power meters caused by submergence in water.

The causes of tsunami-induced fires have not been fully elucidated to date, while most of the causes of earthquake-induced fires have been clarified. The further effort of investigating into fire causes of tsunamiinduced fires is indispensable in order to mitigate fire damage by future earthquakes. One of the very evident tsunami-induced fire causes is flammable gas discharged from unglued and floating liquefied petroleum gas cylinders, which was often seen in the moving pictures taken by many eyewitnesses. Therefore, as an automatic shutdown device of gas leakage has been already developed, these devices should be required to be attached to liquefied petroleum gas cylinders.

The size of fire differs greatly with differences in location (inland versus coastal area) and the difference between an earthquake-induced or a tsunami-induced fire. As for earthquake-induced fires in inland areas, small fires and partially burned fires together accounted for three quarters of the total. By contrast, for tsunami-induced fires, totally burned fires and large-scale fires accounted for three quarters, while the cases of partially burned fires and small fires accounted for only one quarter. This shows the fact that the fire brigades in a coastal area had to devote their manpower and resources for responding to both tsunami disaster and fires, meaning their response capabilities were forced to be dispersed and insufficient in some cases.

The much smaller percentage of the emergency calls as the fire reporting method in the coastal areas translated to substantial delays of fire brigade arrivals and the start of fire fighting on site. This is another key factor that contributed to larger fires in the coastal areas.

As a result, a significant finding from the analysis is the fact that tsunami-induced fires are likely to spread beyond the control of fire brigades. Therefore, the prevention and mitigation of ignition of tsunami-induced fires in the future earthquakes is of great significance.

In conclusion, although this survey did reach a satisfactory level to grasp the general picture of fires following the 2011 Great East-Japan Earthquake, there are still many questions remaining. Therefore, precise fire investigation and further information collection of post-earthquake fires along with scientific clarification and verification of unexplained fire causes in the future are necessary in order to carry on further detailed analysis. The authors will do their best to continue efforts to complete the picture regarding fires following the Great East-Japan Earthquake. 


\section{ACKNOWLEDGMENTS}

The authors wish to express sincere gratitude for understanding and cooperation from the fire departments in the affected areas in regard to the questionnaire survey on fires following the Great East-Japan Earthquake. If otherwise, the analysis in this paper would not have been realized.

\section{REFERENCES}

[1] Fire and Disaster Management Agency, News (136th Edition) on the 2011 off the Pacific coast of Tohoku Earthquake as of August 11, 2011.

[2] Kindai-shobosha, the 2011 Great East-Japan Earthquake, Digest version of "Kindai Shobo" (Modern Fire Administration), January, 2012.

[3] Iwami, T. and Kagiya, K., Analysis on Situation of Fire Outbreak in the 2011 Great East-Japan Earthquake, Proceedings of Symposium on Lessons learned from the 2011 Great East-Japan Earthquake, Architectural Institute of Japan, 2012, pp.363-366.

[4] Investigation Committee of Japan Association for Fire Science and Engineering, Report on Fires in the 2011 Great East-Japan Earthquake (prompt report version), 2011.

[5] Iwami, T., Occurrence Factors and its Mitigating Measures of Conflagrations Following an Earthquake, Proceedings of the 51st Seminar on Fires Science and Engineering, Japan Association for Fire Science and Engineering, 2012, pp.39-47.

[6] Kobe City, Record of Disasters in Kobe caused by the 1995 Kobe Earthquake, 1996.

[7] Ichiguchi, T., Matsumura, S., A New Challenge for Mitigating Building Damage depending on Period of Ground Motion, Study on Trends in Science and Technology, Issue of May\&June, 2012, pp.22-35.

[8] Fire and Disaster Management Agency, the White Book on Fire Service in Japan (2010 Edition). 